\title{
Evalueren en leren van ICT-projecten ${ }^{*}$
}

Wouter Bronsgeest \& Rex Arendsen

\begin{abstract}
ICT-projecten van de overheid zijn geregeld in het nieuws vanwege problemen met de kwaliteit van het eindproduct, tijdigheid van opleveren of kosten die gemaakt worden. De commissie-Elias beveelt aan om meer te evalueren en daarvan vervolgens te leren, maar geeft niet aan hoe. De vraag is wat een goede evaluatie van een ICT-project bij de overheid is. Een evaluatie zal aan een aantal specifieke kenmerken moeten voldoen. Daartoe wordt in dit artikel een kader gepresenteerd voor het onderzoek naar evaluaties van ICT-projecten projecten, gebaseerd op kennis vanuit meerdere wetenschappelijke disciplines. Het waarnemingskader omvat handreikingen om de methode van evalueren, en het evaluatieproces en de inhoudelijke criteria in de evaluatie te beoordelen. Na toepassing van het kader in een documentanalyse met inhouds-analytische technieken blijkt dat evaluaties nauwelijks worden gedeeld, zonder duidelijke aanleiding, afbakening of onderzoeksopdracht starten en beperkt conclusies en reflecties bevatten. Er is dan ook veel ruimte voor substantiële verbeteringen.
\end{abstract}

\section{Aandacht voor ICT-projecten bij de overheid}

Vijf jaar na de start van de commissie-Elias zijn kwaliteit en voortgang van ICTprojecten bij de overheid nog steeds een actueel onderwerp. Elias onderzocht de kwaliteit van ICT-projecten en doet uitspraken over de maatschappelijke effecten van mislukte ICT-projecten (Kamerstukken II 2014/15, 33326, nr. 5). Producten uit een ICT-project worden immers gebruikt door overheidsorganisaties in hun processen, en de kwaliteit van deze ICT-producten heeft impact op het functioneren van de organisatie, en dus op de dienstverlening aan burger en bedrijf.

Veel ICT-projecten komen in de problemen vanwege de kwaliteit van het eindproduct, tijdigheid van opleveren of kosten die gemaakt worden (Olsthoorn \& Kakebeeke, 2018). Een van de aanbevelingen van Elias is dat nadrukkelijker moet worden gekeken naar de wijze van uitvoering van ICT-projecten. De Algemene Rekenkamer (ARK), Bureau Gateway en de Auditdienst Rijk (ADR) doen dergelijke onderzoeken. De commissie adviseerde tevens om het Bureau ICT-toetsing (BIT) op te richten als extra toezichthoudende organisatie. BIT-toetsen die het bureau

* Dr. W.L. Bronsgeest is verbonden aan het Center for eGovernment Studies (CFES) van de Universiteit Twente, en duovoorzitter van de Koninklijke Nederlandse Vereniging van ICT- en Informatieprofessionals (KNVI). Hij is tevens werkzaam als lid van het managementteam van de Directie IV van de Belastingdienst.

Prof. dr. ir. R. Arendsen is als hoogleraar Maatschappelijke en historische context van belastingrecht verbonden aan de Universiteit Leiden. Hij is tevens werkzaam als adviseur bij het Centre for Tax Policy and Administration bij de OESO in Parijs. 
uitvoert, genereren inmiddels meer aandacht voor ICT-projecten van de overheid. In een tussentijdse analyse in 2016 wordt aangegeven dat geagendeerde BIT-toetsen in de Tweede Kamer ook aandacht krijgen voor vervolgacties. Toch lijkt het te vroeg om te concluderen dat aanbevelingen in toetsrapporten en aandacht voor bevindingen in de Tweede Kamer ook daadwerkelijk leiden tot een grotere slaagkans, betere projectbeheersing en het vergroten van lerend vermogen (VKA \& Berenschot, 2016; AEF, 2018).

De toezichthouders zien toe op ICT-overheidsprojecten, en beoordelen succes en falen aan de hand van diverse soorten evaluaties. In deze evaluaties zijn gerealiseerde effecten, opgeleverde projectresultaten en ook uitgevoerde (interne) projectevaluaties onderwerp van onderzoek. Kwalitatief goede evaluaties, zowel van de eigen organisatie als van een tweede- of derdelijns toezichthouder, kunnen een bron van aanbevelingen zijn en kunnen dus helpen om van te leren. De vraag is wat goede evaluaties zijn. De Commissie Elias adviseert bijvoorbeeld dat er meer geëvalueerd moet worden, maar geeft niet aan hoe de kwaliteit van evalueren kan worden vergroot. De centrale vraag in deze bijdrage is dan ook: Wat is een goede evaluatie van een ICT-project bij de overheid? Met andere woorden, welke kenmerken in de aanpak van evaluaties helpen om een kwalitatief goede evaluatie uit te voeren?

Deze bijdrage is gebaseerd op onderzoek dat tussen 2009 en 2016 is uitgevoerd naar de kwaliteit van evaluaties van projecten met een ICT-component bij de overheid (Bronsgeest, 2016). Daarbij is aan de hand van een wetenschappelijk waarnemingskader een groot aantal evaluaties beoordeeld. In deze bijdrage schetsen we in het kort de beginselen van theorieën over evalueren in relatie tot het evalueren van ICT-projecten, en beschrijven we op hoofdlijnen het beoordelingskader en de onderzoeksaanpak die zijn toegepast voor de analyse van de betreffende evaluatierapporten. Aan de hand van dit beoordelingskader kan de kwaliteit van evaluaties worden beoordeeld en kunnen verbetersuggesties worden aangereikt.

\section{Evaluatietheorie}

Evaluaties zijn een voorbeeld van praktijkgericht onderzoek vanwege hun doelstelling een bijdrage te leveren aan een analyse of een interventie om een bepaalde (praktijk)situatie te veranderen. Bij evalueren staan zowel producten van menselijke activiteiten centraal als de studie van de mens als individu en in groepen. Evalueren is daarmee een verschijningsvorm binnen de ervaringswetenschappen, namelijk de toegepaste- en de gedragswetenschappen. Vanuit het belang van een systematische onderzoeksaanpak is de definitie van Stufflebeam en Shinkfield (2007) uitgangspunt: 'Evaluation is the systematic assessment of an object's merit, worth, probity, feasibility, safety, significance and/or equity.' Stufflebeam en Shinkfield geven handvatten voor het uitvoeren van evaluaties door handelingen, proces, effect en efficiëntie van het onderzoeksobject (bijvoorbeeld een project) te operationaliseren. Deze definitie incorporeert elementen van 
andere definities in het vakgebied. Ten eerste die van Scriven (1991), die in de Evaluation Thesaurus over evalueren schrijft: '(...) the process of determining the merit, worth and value of things, and evaluations are the products of that process.' Ten tweede die van Boulmetis en Dutwin (2005), die aangeven dat evalueren een systematisch proces is ten behoeve van 'collecting and analysing data to determine whether and to what degree objectives have been or are being achieved', en 'collecting and analysing data in order to make a decision'. Deze definities incorporeren ook de denkbeelden van Tyler uit 1930 over het meten van behaalde doelen, de zogenoemde Goal-Based-evaluatie (Scriven, 1991).

Scriven (1991) benadrukt dat het evaluatiewerkveld breed is: '(...) evaluation is not (...) a branch of applied social sciences, nor a study of human interventions, nor a subject whose intellectual origins are in social sciences. It is a much older and more general discipline. Not only do systematic approaches to product and personnel evaluation predate the whole social science by millennia, but so do the intellectual roots of the core discipline, the study of its methodology and models'. Scriven definieert evalueren als een transdiscipline die in meerdere wetenschappelijke stromingen voorkomt. Hij neemt daarmee stelling in de discoursen over evalueren die sinds het ontstaan van het vakgebied bestaan in de literatuur.

De diverse theorieën over evalueren leveren veel kennis op over de uitvoering van evaluatieonderzoek. In de literatuur is daarnaast veel geschreven over de afbakening van projecten. Theorie met een helder overzicht van kaders en bijpassende criteria om de kwaliteit van evaluaties van projecten met een ICT-component te toetsen is echter nauwelijks beschikbaar. Evaluatiestandaarden en -frameworks gaan wel in op het proces van evalueren, maar niet op aspecten waarmee uitspraken kunnen worden gedaan over projectproducten en -inhoud, namelijk de voortbrenging van ICT-producten en -diensten. Het door ons ontwikkelde waarnemingskader is dan ook, naast de kennis over hoe geëvalueerd moet worden, mede gebaseerd op inhoudelijke criteria uit de vakgebieden (1) accountancy en (IT-)auditing, (2) gedragswetenschap, (3) bestuurs- en organisatiewetenschap, en (4) kwaliteitsmanagement.

Mulder en Mulder (2013) geven aan dat het beschouwen van alleen de ICT-realisatiefase van een project onvoldoende is. Juist de fase dat eisen en wensen vanuit de opdrachtgever en gebruiker worden geformuleerd tot en met de fase dat nieuwe processen met de bijbehorende ICT-voorzieningen worden geïmplementeerd, kennen belangrijke randvoorwaarden om een ICT-oplossing tot een succes te maken. In dit onderzoek reden om Dit is dan ook de reden om in dit onderzoek te spreken van 'projecten met een ICT-component', waarbij de gehele keten van het voortbrengen van ICT-voorzieningen wordt beschouwd. Deze keten wordt daarmee tevens onderdeel van het te ontwikkelen waarnemingskader.

Vanuit bestaande evolutietheorieën kunnen drie hoofdpunten worden gedestilleerd om de kwaliteit van evaluaties te beoordelen.

Ten eerste kan worden gekeken naar de methode van evalueren. De vraag is dan of gebruik is gemaakt van een wetenschappelijke aanpak met een heldere pro- 
bleemstelling, doelstelling en vraagstelling, en of de evaluatieaanpak herhaalbaar is. Dit sluit aan bij de definitie van evalueren als een vorm van praktijkgericht toegepast onderzoek (Verschuren \& Doorewaard, 2007).

Ten tweede is het gebruikte evaluatieproces een hulpmiddel om de kwaliteit van een uitgevoerde evaluatie te toetsen. Evalueren is te beschrijven als een proces, een afgeleide van de interventiecyclus die bijvoorbeeld bij organisatiediagnoses wordt gebruikt. Een dergelijke procesaanpak helpt bij het typeren van de evaluatie en het bepalen van het moment van evalueren ten opzichte van de status van een project (Van Strien, 1986).

Een derde hoofdpunt bestaat uit inhoudelijke kwaliteitscriteria. Vanuit de theorieën over evalueren en aanpalende wetenschappelijke aandachtsgebieden is een inhoudelijk waarnemingskader op te stellen. Vanuit deze wetenschappelijke bronnen zijn specifieke deelaspecten te achterhalen die onderdeel kunnen zijn van evaluaties van projecten met een ICT-component.

\section{Het beoordelingsinstrument: een waarnemingskader}

Vanuit de hiervoor genoemde literatuur is een waarnemingskader uitgewerkt. Een dergelijk kader bestond nog niet. Het kader is opgebouwd uit 21 hoofdaspecten die zowel de stappen van de hiervoor genoemde interventie-cyclus als de fases van het voortbrengen van ICT-voorzieningen volgen vanaf het moment dat de opdrachtgever wensen en eisen formuleert (Bronsgeest, Arendsen, \& Van Dijk, 2017).

Per hoofdaspect zijn vervolgens meerdere specifieke geoperationaliseerde onderwerpen uit de literatuur afgeleid, die verder geïndexeerd zijn.

Dit waarnemingskader is vervolgens in panelsessies van tien deskundigen uit wetenschap en praktijk getoetst op facevaliditeit en inhoudsvaliditeit. Na een selecte steekproef van vijf evaluatierapporten is eerst een inhoudelijke analyse gedaan om de toepasbaarheid van het waarnemingskader te testen. Ook die is in een panelsessie getoetst op facevaliditeit en inhoudsvaliditeit.

Tijdens het onderzoek is een derde toetsing gedaan op validiteit en betrouwbaarheid door de intercodeursbetrouwbaarheid vast te stellen. Deze is vastgesteld op $\mathrm{PA}_{\mathrm{o}}=.76 . \mathrm{PA}_{\mathrm{o}}=\mathrm{A} / \mathrm{n}$, waarbij $\mathrm{A}$ het aantal overeenkomsten is tussen de codeurs en $\mathrm{n}$ het totaalaantal onderdelen dat gecodeerd is door de codeurs. Het percentage overeenkomstige antwoorden gegeven door de eerste onderzoeker en de tweede codeur bedraagt $76 \%$.

\section{Opzet van de meta-evaluatie}

Onderzoek naar de kwaliteit van evaluaties van projecten met een ICT-component is gedaan met een evaluatief onderzoek in de vorm van een meta-evaluatie aan de hand van het waarnemingskader. Deze aanpak valt uiteen in een aantal stappen. 
Tabel 1 Hoofdpunten waarnemingskader

Waarnemingskader (samenvatting)

I. Op welke wijze is aandacht gegeven

... vanuit welke politiek vraagstelling de evaluatie wordt uitgevoerd?

2. ... aan het besluitvormingsproces om tot de evaluatie te komen?

3. Wie is de opdrachtgever van de evaluatie, en wat is zijn mandaat binnen de organisatie?

4. Welke partij voert de evaluatie uit?

5. Wat is de vraagstelling en wat is de probleemstelling die als opdracht voor het betreffende evaluatieonderzoek is gebruikt?

6. Wat is de afbakening van de evaluatie?

7. Welk instrument is gebruikt (en in welke mate is dat toegepast)?

8. Vanuit welk theoretisch inhoudelijk kader is gewerkt?

9. Vanuit welk evaluatiemodel is gewerkt?

10. Welke evaluatietechnieken zijn gebruikt?

II. Op welke wijze

$\ldots$ is de evaluatie uitgevoerd? Welke typen evaluaties zijn toegepast, en met welke diepgang?

12. ... is aandacht gegeven aan de interne context (waaronder proces, eindproduct, kwaliteit, competenties, gedrag, standaarden), en

13. aan de externe context (bijvoorbeeld wet- en regelgeving) van het te evalueren project?

$14 . .$. is aandacht gegeven aan de kerntaak en het volwassenheidsniveau van de organisatie?

$15 . .$. is in de evaluatie aandacht gegeven aan de te realiseren bedrijs- of organisatiedoelstelling in relatie tot de projectdoelstelling?

16. ... is aandacht gegeven aan de methode( $\mathrm{n}$ ) van controle en beheersing (governance) en de mate waarin bijvoorbeeld risico's worden beheerst binnen het project of organisatie?

17. ... is aandacht gegeven aan het portfolio van projecten?

18. Wat zijn kenmerken van het evaluatierapport (waaronder indeling en hoofdstukken)?

19. Op welk moment is geëvalueerd?

20. Wat zijn kenmerken van het evaluatieproces en welke aanpak is gevolgd voor het uitvoeren van de evaluatie?

21 . Is er aandacht voor de evaluator?

Tijdens een evaluatie van een project met een ICT-component wordt gekeken naar de verschillende ontwikkelfases ten behoeve van een ICT-voorziening (Obers \& Achterberg, 2009). Deze ontwikkelfases zijn: (a) de totstandkoming van een probleemdefinitie, (b) opstellen van een eventuele businesscase, (c) het in kaart brengen van de eisen vanuit de primaire processen (de 'requirements'), (d) ICTrealisatie en de daaropvolgende ingebruikname van proces en ICT-ondersteuning. In het onderzoek is gekeken naar evaluaties van startende, lopende én afgeronde (deel)projecten met een ICT-component.

Parallel aan het opzetten van het waarnemingskader zijn cases geselecteerd. In dit onderzoek is het object van onderzoek het evaluatierapport. Gestart is met het vaststellen van de populatie. Die populatie bestaat uit projecten van de grote ICTprojecten rapportage van het Rijk (TK, 2010), aangevuld met de uitvraag van een geschatte populatie beschikbare rapporten van e-overheidsprojecten, uitvoerings- 
organisaties (ZBO's én de diensten en instellingen van ministeries) en gemeenten.

Aan de hand van een gestratificeerde aselecte steekproef zijn vervolgens evaluatierapporten opgevraagd. Daar waar de onderzoekspopulatie geen indicatie gaf van uitgevoerde en geëvalueerde projecten, is deze steekproef toegepast op organisaties, waarna per organisatie rapporten zijn opgevraagd.

De respons op de uitvraag van rapporten was divers. De laagste respons was 30 procent. Deze lage respons viel op, omdat het hier de aanschrijving betrof van expliciet genoemde rapporten uit de lijst van grote ICT-projecten. Dat is een lage respons in vergelijking met de percentages van de andere groepen. De respons van e-overheidsprojecten, uitvoeringsorganisaties en gemeenten was respectievelijk 43, 68 en 68 procent. De uitvraag heeft geleid tot 88 te onderzoeken evaluatierapporten van respectievelijk departementen, e-overheidsprojecten, uitvoeringsorganisaties en gemeenten.

Voor het analyseren van de evaluatierapporten is documentanalyse toegepast, met gebruik van inhouds-analytische technieken. Daarbij is de onderzoeksmethode van Neuendorf (2002) toegepast, die een negental onderzoeksstappen voorschrijft en daarmee voorziet in de toepassing van de wetenschappelijke methode. Daardoor is de documentanalyse wetenschappelijk onderbouwd, herhaalbaar en uitvoerbaar. Door de keuze van evaluatierapporten als object van onderzoek is het mogelijk om met documentanalyse niet alleen een herhaalbaar onderzoek op te zetten, maar ook om een groot aantal rapporten te analyseren en daarmee patronen te vinden die uitspraken doen over de kwaliteit van de uitgevoerde evaluaties. Deze patronen kunnen op hun beurt ook worden gebruikt voor het beoordelen van andere evaluatierapporten. Tot slot kunnen de patronen helpen bij het beter uitvoeren van projecten, omdat uit bevindingen uit evaluaties ook verbeteringen te formuleren zijn voor nieuwe projecten.

\section{Toepassing van het instrument: wat is de kwaliteit van uitgevoerde evaluaties?}

De meta-analyse geeft inzicht in de kwaliteit van de uitgevoerde evaluaties (Bronsgeest, 2016). De resultaten laten meerdere kleinere en grotere omissies zien, waarvan we de vier belangrijkste beschrijven.

\section{Valse start in de eerste fasen van evaluatieonderzoek van projecten}

In het onderzoek is het uitvoeren van evaluaties van projecten geoperationaliseerd aan de hand van een procesbenadering. Daarbij worden fases onderscheiden die zijn afgeleid uit de interventiecyclus (Verschuren \& Doorewaard, 2007). Deze fases maken de structurering van evaluatieonderzoek van een project mogelijk, geven duiding aan het iteratieve proces van het uitvoeren van het onderzoek, en faciliteren het reflecteren op het gehele proces.

Zo is slechts in 35 van de 88 rapporten beschreven wat de aanleiding is voor het doen van de evaluatie. De besluitvorming voorafgaand aan de evaluatie kan rele- 
vant zijn, geeft duiding van de relevantie en het belang van de evaluatie aan, en kan aangeven of er een strategische of politieke reden is om wel of juist niet te evalueren. Vervolgens blijkt dat ook het opdrachtgeverschap van evaluaties niet altijd helder beschreven is. Van 33 van de 88 rapporten is onbekend wie de opdrachtgever van de evaluatie is. Van rapporten waarin wel een opdrachtgever is vermeld, is vaak een organisatieonderdeel genoemd. In slechts 14 rapporten komt een naam voor.

Evaluaties zijn praktijkgerichte toegepaste onderzoeken. Het helpt dan ook om een gestructureerde (onderzoeks)aanpak toe te passen bij evaluaties. In de analyse van de rapporten blijkt echter dat 23 van de 88 evaluaties zonder doelstelling, probleemstelling en vraagstelling starten. In vijf rapporten is een doelstelling terug te vinden. In de andere rapportages is in veel gevallen alleen een vraagstelling of probleemstelling beschreven. Slechts 16 rapporten beschrijven een probleemstelling en vraagstelling. De vraag is of daarmee voldoende richting wordt gegeven aan het onderzoek. Er bestaat een mogelijkheid dat in bijvoorbeeld een opdrachtbrief of plan van aanpak wel meer richting wordt gegeven aan de evaluatie; dat is echter buiten de afbakening van ons onderzoek gebleven.

\section{Onduidelijke evaluaties}

Het uitvoeren van een onderzoek houdt ook in dat sprake is van een vooraf beschreven, herhaalbare aanpak. Een dergelijke aanpak beschrijft in een optimale situatie ook afwegingen op welke wijze en met welk instrumentarium het onderzoek wordt uitgevoerd. In de geanalyseerde evaluatierapporten is daarvan niet altijd sprake. In 25 evaluatierapporten krijgt het evaluatieproces aandacht. Aanvullend zijn er acht rapporten waarin wordt gerefereerd aan een wetenschappelijke aanpak, en waarin een methodisch kader wordt opgesteld om te evalueren. Met andere woorden, in 32 van de 88 evaluaties is aandacht voor de wijze waarop de evaluatie kan worden uitgevoerd. Daarbij is er nog geen aandacht voor uitspraken over evaluatietechnieken voor het verzamelen, structureren of beoordelen van data. In 56 evaluatierapporten is dat beschreven. Dat wil overigens niet zeggen dat er geen evaluatietechnieken zijn toegepast. Die zijn namelijk vaak wel te herleiden uit de tekst.

\section{Beperkte afbakening van de evaluatie}

Een evaluatieonderzoek is op meerdere wijzen af te bakenen. De meest eenvoudige wijze van afbakenen is de onderverdeling van proces, product en people (Cooper \& Kleinschmidt, 1986). De afbakening op proces houdt in dat een evaluatie de focus legt op de wijze waarop een project met een ICT-component is verlopen, welke fases het project kent en op welke wijze een project tot tussen- en eindproducten is gekomen. De aandacht voor product houdt in dat een evaluatie zich meer richt op de kwaliteit en de specificaties van opgeleverde producten en diensten van een project. Aandacht voor people houdt in dat wordt gekeken naar de menselijke factor, waaronder samenwerking, expertises en onderlinge afstemming en communicatie. Alle drie deze invalshoeken zijn onderdeel van het waarnemingskader. 
Uit de analyse van de 88 evaluatierapporten blijkt dat er vooral gekeken wordt naar het eindresultaat van een project. Veel evaluaties van projecten refereren aan projectmanagementmethoden (56 rapporten), waaronder Prince2 (34 rapporten), om een uitspraak te doen over de uitvoering van een project. In 25 evaluatierapporten wordt gekeken naar de wijze waarop een project (het proces) is uitgevoerd. Opvallend is dat in de afbakening van evaluaties zelden aandacht is voor de mensen van het project en de wijze waarop zij samenwerken. Tot slot ligt de nadruk van veel evaluaties op één van de drie onderwerpen, en maar zelden op twee of drie van deze genoemde onderwerpen.

\section{Ontbrekende conclusies, aanbevelingen en meta-bevindingen}

Opvallend is dat in slechts 39 rapporten conclusies worden geformuleerd en in 38 rapporten aanbevelingen worden gedaan. De reden dat juist deze hoofdstukken ontbreken, is onbekend. Het valt wel op dat in 88 rapporten weinig van de gelegenheid gebruik wordt gemaakt om de opdrachtgever of organisatie van advies te voorzien. Ook een reflectie op het proces van evalueren of de rol die de evaluator heeft gehad op het project tijdens de evaluatieperiode, komt nauwelijks voor, namelijk slechts 11 keer. Dat geldt zowel voor de uitvoerder van de evaluatie als voor de opdrachtgever. Bewijs voor enige vorm van reflectie door de evaluator is gevonden in 35 rapporten in de vorm van een persoonlijke opmerking van de onderzoeker.

\section{Conclusie en aanbevelingen}

We zien een groeiende aandacht voor het evalueren van projecten met een ICTcomponent. Door deze aandacht en diverse aanbevelingen voor betere evaluaties mag een steile leercurve worden verwacht. Uit het hier gepresenteerde onderzoek blijkt dat er nog veel ruimte is voor verbetering en dat er sprake is van veel 'laaghangend fruit' in de evaluatieaanpak voor projecten met een ICT-component bij de overheid. Wij presenteren daarvoor de volgende suggesties.

\section{a. Verbeter de onderzoekskwaliteit}

De kwaliteit van evaluaties is onvoldoende door een vaak onvolledige onderzoeksopzet, eenzijdige afbakening, onvoldoende aandacht voor processtappen en beperkte diepgang op inhoud. Gekoppeld aan het feit dat veel evaluaties worden opgestart zonder een duidelijk in de tekst herleidbare probleemstelling en vraagstelling, versterkt de gedachte dat evalueren vaak meer voor de vorm wordt gedaan dan om ervan te leren. Vanuit het onderzoek is echter duidelijk geworden dat in veel evaluatierapporten moeite wordt gedaan om goed onderbouwde bevindingen te formuleren. Met aandacht voor de kwaliteit van de onderzoeksopzet kunnen evaluaties verbeteren, en vervolgens een betere basis vormen voor verbetering en reflectie. 


\section{b. Manage het evaluatieproject}

Naast aandacht voor de kwaliteit van de onderzoeksopzet is het expliciet maken van de evaluatieaanpak en variëteit in instrumenten ook eenvoudig toe te passen. Pas daarna kunnen gesprekken, interviews, groepssessies en online vragenlijsten worden toegepast. En aan het einde van het evaluatieproces is aandacht voor goede conclusies en aanbevelingen en reflectie op de evaluatie een processtap die praktisch te organiseren is en waarde toevoegt.

\section{c. Gebruik een waarnemingskader}

Om een evaluatie kwalitatief te verbeteren kan gebruik worden gemaakt van het beschreven geoperationaliseerde en geïndexeerde waarnemingskader. Dat is speciaal ontwikkeld om zowel de wijze waarop de evaluatie is uitgevoerd te beoordelen, als om een aantal inhoudelijke punten mee te geven die belangrijk zijn voor de evaluatieprojecten met een ICT-component. De toepassing van een dergelijk waarnemingskader geeft extra mogelijkheden tot breed kijken op inhoud, en tevens verdieping daar waar noodzakelijk. Ook geeft het de gelegenheid voor opdrachtgever en evaluator om bewust te kiezen waar wel en waar niet naar te kijken in de evaluatie.

\section{d. Vorm een leercirkel}

Op De beschreven methode laat zien hoe je een evaluatie inhoudelijk kunt beoordelen en met welk instrument. Aan de hand van een documentanalyse kan een meta-evaluatie worden uitgevoerd. De aanpak voor een documentanalyse is goed beschreven, en er bestaat veel literatuur over. Met een meta-evaluatie wordt de conditie geschapen om een double-loop of zelfs een triple-loop leerervaring te faciliteren. Met andere woorden, door rode draden en patronen uit evaluaties van geëvalueerde projecten te halen kunnen nieuwe inzichten ontstaan. Zowel voor de evaluator als voor de opdrachtgever en de projectleider.

Kortom, kennis over het evalueren van projecten met een ICT-component helpt ook bij het verbeteren van evaluaties én bij de uitvoering van projecten. Als een kader helder is, kunnen opdrachtgevers en projectleiders daar weer hun voordeel mee doen. En dus blijven leren.

\section{Literatuur}

AEF (Andersson Elffers Felix). (2018). Eindrapport Evaluatie Bureau ICT-Toetsing. Utrecht. Boulmetis, J., \& Dutwin, P. (2005). The ABCs of evaluation: Timeless techniques for program and project managers (2nd edition). San Francisco: Jossey Bass/John Wiley \& Sons.

Bronsgeest, W.L. (2016). Meer vorm dan inhoud. Enschede: Gildeprint.

Bronsgeest W.L., Arendsen R., \& Dijk, J.A.G.M. van. (2017). Towards Participatory EGovernment? Learning from E-Government Project Evaluations. In P. Parycek et al. (Eds.), Electronic Participation. ePart 2017. Lecture Notes in Computer Science, vol. 10429. Cham: Springer. 
Cooper, R.C., \& Kleinschmidt, R.J. (1986). An investigation into the new product process: Steps, deficiencies, and impact. Journal of Product Innovation Management, 71(3), 851-986.

Mulder, H., \& Mulder, T. (2013). Waarom grote ICT-projecten vaak mislukken. Informatie, maandblad voor de Informatievoorziening. Den Haag, Sdu.

Neuendorf, K.A. (2002). The content analysis guidebook. Thousand Oaks, CA: Sage Publications.

Obers, G., \& Achterberg, K. (2009). Procesarchitectuur als veranderinstrument: Strategische ambities realiseren met bedrijfsprocessen. Zaltbommel: Van Haren Publishing.

Olsthoorn, S., \& Kakebeeke, P. (2018, 2 juli). Grote ICT-projecten zeker 1 miljard duurder. Financieel Dagblad (FD). https://fd.nl/ondernemen/1259605/grote-ict-projectenoverheid-zeker-1-mrd-duurder-dan-begroot

Scriven, M. (1991). Evaluation thesaurus (4th edition). Newbury Park: Sage Publications.

Strien, P.J. van. (1986). Praktijk als wetenschap: Methodologie van het sociaal-wetenschappelijk handelen. Assen: Van Gorcum.

Stufflebeam, D.L., \& Shinkfield, A.J. (2007). Evaluation, theory, models \& applications. San Francisco: Jossey-Bass.

TK (Tweede Kamer der Staten Generaal) (2010-0000355991). (2010). Rapportage Grote ICT-projecten. Den Haag.

TK (Tweede Kamer der Staten Generaal) (TK 33 326, nr. 5). (2014). Parlementair onderzoek naar ICT-projecten bij de overheid, eindrapport, vergaderjaar 2014-2015, 33326, nr. 5. Den Haag.

Verdonk, Klooster \& Associates (VKA) \& Berenschot. (2016). Ervaringen met BIT-toetsen: Praktische lessen voor CIO's en projectverantwoordelijken.

Verschuren, P., \& Doorewaard, H. (2007). Het ontwerpen van onderzoek (4e druk). Den Haag: Boom Lemma. 